\title{
Inter-gender differences in the formation of anteroposterior spinal curvatures in people practicing ballroom dancing
}

\author{
EWA PUSZCZAŁOWSKA-LIZIS ${ }^{1 *}$, MARZENA MÓL ${ }^{2}$, JAROSŁAW OMORCZYK ${ }^{3}$ \\ ${ }^{1}$ Medical College, Institute of Health Sciences, University of Rzeszów, Rzeszów, Poland. \\ ${ }^{2}$ Senso Dance Studio in Rzeszów, Poland. \\ ${ }^{3}$ Faculty of Physical Education and Sports, Institute of Sport, University School of Physical Education, Kraków, Poland.
}

\begin{abstract}
Purpose: The study aimed to assess the formation of the spinal anteroposterior curvatures in people practicing ballroom dancing. Methods: The study group comprised 98 people practicing ballroom dancing (58 W, $40 \mathrm{M}$; aged 35-45 years). Digital inclinometer "Baseline" was used as primary research tool. The data were analyzed based on Student's $t$-test, Mann-Whitney $U$-test and Pearson Chi-square test. Results: Statistically significant inter-gender differences were in the values of angles determining inclination of lumbosacral section of the spine $(p<0.001)$, the lumbar lordosis curvature $(p<0.001)$ as well as the compensation ratio $(p=0.002)$. Statistically significant dependences between the types body posture and gender $(p=0.005)$ were noted. Conclusions: Women practicing ballroom dancing are distinguished with increased inclination of lumbosacral section of the spine and deeper lumbar lordosis, while men are characterized with shallowed lumbar lordosis. Women are more likely to have lordotic body posture while men are characterized by balanced body posture. The prevalence of body posture subtypes is not dependent on gender.
\end{abstract}

Key words: lumbosacral inclination, thoracic kyphosis, lumbar lordosis, dance

\section{Introduction}

The constant focus on improving psychomotor skills through dance training enables the dancers to develop and maintain a high level of fitness. Character and time spent on dance training can have a significant impact on the body posture, including angular values of spinal curvatures in the sagittal plane. Figures and steps in ballroom dance require the dancers to have flawless posture while performing. They strive to obtain an ideal position by, e.g., lifting their heads, squeezing scapulae and opening their chest. Training classic positions requires long-term static muscle work of the spine and lower limbs stabilizers, including spinal erector, latissimus dorsi, trapezius, serratus anterior, the abdominal muscles as well as the hip flexors and exten- sors [4]. During training, athletes also focus on increasing the mobility of the spine, hip, knee and ankle joints, which can lead to muscular misbalance resulting in body posture disorders [17]. Practicing ballroom dancing forces long-lasting and non-physiological loading of specific parts of the locomotor system. Regardless of health consequences, dancers often strive to achieve better rotation of the torso desired in classical dance by incorrectly positioning the structures of the spine and pelvis. In men, incorrect technique of lifting a partner affects overstretching of the lumbar spine [12]. Jumps are components of dancers expressive movements, which generate high values of the vertical component of the ground reaction force, especially during the landing phase. They may result in overloading the spine, especially in the case of deviations from the physiological curvatures resulting in tissue

\footnotetext{
* Corresponding author: Ewa Puszczałowska-Lizis, Medical College, Institute of Health Sciences, University of Rzeszów, ul. Warzywna 1A, 35-959, Rzeszów, Poland. Phone: +48 882056555, e-mail: ewalizis@poczta.onet.pl

Received: July 2nd, 2020

Accepted for publication: October 5th, 2020
} 
wear and tear as well as micro-injuries and locomotor injuries [9].

According to Kiefer et al. [14], Rickman [24], Fredryk and Smol [8] and Paris-Alemany et al. [20], dancers are characterized by the ability to detect even small disturbances in body stability and elicit precise and fast postural response. Efficient control of vertical posture is one of the basic motor skills of ballroom dancers. It requires constant activity of postural muscles, which prevents the center of gravity from moving beyond the limits of stability. Perrin et al. [21] claim that this may be due to the nature of dance training, especially when training techniques require dynamic stability on the one hand, while flexibility and sufficiently large ranges of movement in the joints on the other. According to Kiefer et al. [14], from a mechanical point of view, the ability to maintain balance is the result of the effective response of the musculoskeletal system to external stimuli and strong proprioception.

Specific biomechanical requirements imposed on the body, often associated with exceeding the limits of anatomical structures capabilities, technical errors and hard training conditions, predispose to body posture disorders. Only few reports are available on the assessment of body posture, including anteroposterior curvature of the spine in adult dancers. The authors of the few scientific publications mostly focus on this issue in relation to children and adolescents practicing ballet [13], [18], [23]. It may stem from the fact that these age groups of dancers are the most numerous and their spine is flexible and prone to deformations. However, it is worth keeping in mind that despite the lack of tangible developmental changes within the body posture during adolescence, muscle and the capsule-ligament apparatus begin to weaken, with involution processes starting after the age of 45 and related degenerative changes occurring in the joints. Therefore, people before the age of 45 , especially between 35 and 45 years of age, need to particularly care for the somatic condition in order to maintain morphofunctional fitness and related body posture at an optimal level in relation to age. It is particularly important for people who take up various forms of physical ac- tivity. Improper body work and, therefore, improperly conducted or even planned training can cause various failures, including postural disorders. The above considerations became the reason for taking up the topic of the study aimed to assess the formation of the anteroposterior curvatures of the spine in people practicing ballroom dancing.

The aim of the present study was to answer whether people practicing ballroom dance experience intergender differences in values of thoracic kyphosis, lumbar lordosis angles, and compensation ratio, whether gender of the studied subjects determine the frequency of deviations in the lumbosacral inclination, the shape of the curvature of the thoracic kyphosis and lumbar lordosis. Another questions were whether the prevalence of particular categories of anteroposterior curvature of the spine depend on gender and whether the incidence of individual types and subtypes of body posture depend on the gender of the study subjects?

\section{Materials and method}

\section{Participants}

The study group comprised 98 people $(58 \mathrm{~W}, 40 \mathrm{M})$, attending ballroom dancing classes at Senso Dance Studio in Rzeszów. The selected group was subsequently verified in terms of its compliance with pertinent criteria:

- inclusion criteria: age range of 35-45 years, lack of any diseases and/or injuries of the musculoskeletal system, confirmed through an interview; practicing ballroom dancing for a minimum period of 10 years, 3 times a week for 2 hours;

- exclusion criteria: exclusion from dance training due to injury for more than 3 weeks in the last six months; pregnancy; refusal to participate in the trial.

The mean age of women was $39.12 \pm 3.37$ years while the mean age of men was $40.10 \pm 3.81$ years. The age did not differentiate between the surveyed women and men $(p=0.243)$ (Table 1$)$.

Table 1. Age of the study subjects

\begin{tabular}{|l|c|c|c|c|c|c|c|}
\hline \multicolumn{1}{|c|}{ Gender } & $\bar{x} \pm \mathrm{SD}$ & Max-min & $\mathrm{Q}_{25}$ & $\mathrm{Me}$ & $\mathrm{Q}_{75}$ & $Z$ & $p$ \\
\cline { 1 - 8 } Women & $39.12 \pm 3.37$ & $45.00-35.00$ & 36.00 & 39.00 & 42.00 & \multirow{2}{*}{-1.17} & \multirow{2}{*}{0.243} \\
\cline { 1 - 6 } & $40.10 \pm 3.81$ & $45.00-35.00$ & 36.50 & 39.00 & 44.00 & & \\
\hline
\end{tabular}

Abbreviations: $\bar{x}$ - arithmetical mean value; $\mathrm{SD}$ - standard deviation; max - maximum value; min - minimum value; $\mathrm{Q}_{25}$ - lower quartile; Me - median; $\mathrm{Q}_{75}$ - upper quartile; $Z$ - value of the Mann-Whitney $U$-test statistic; $p$ - probability value. 
Table 2. Comparison of select bodily characteristics in respective groups of subjects

\begin{tabular}{|l|c|c|c|c|c|c|c|}
\hline \multirow{2}{*}{ Gender } & $\bar{x} \pm \mathrm{SD}$ & $\max -\min$ & $\mathrm{Q}_{25}$ & $\mathrm{Me}$ & $\mathrm{Q}_{75}$ & $Z$ & $p$ \\
\cline { 2 - 7 } & \multicolumn{7}{|c|}{ Body mass [kg] } \\
\hline Women & $60.76 \pm 5.66$ & $72.00-45.00$ & 58.00 & 60.00 & 64.00 & \multirow{2}{*}{-7.73} & \multirow{2}{*}{$<0.001^{*}$} \\
\hline Men & $79.40 \pm 10.46$ & $104.00-62.00$ & 72.00 & 77.50 & 84.00 & \\
\hline & $167.20 \pm 6.06$ & $177.00-154.00$ & 163.00 & 169.00 & 171.00 & \multirow{2}{*}{-6.40} & $<0.001^{*}$ \\
\hline Women & $178.00 \pm 6.95$ & $193.00-167.00$ & 173.50 & 176.00 & 182.50 & & \\
\hline Men & $21.74 \pm 2.31$ & $27.50-18.20$ & 19.70 & 21.55 & 23.20 & \multirow{2}{*}{-5.32} & $<0.001^{*}$ \\
\hline
\end{tabular}

Abbreviations: $\bar{x}$ - arithmetical mean value; $\mathrm{SD}$ - standard deviation; $\max$ - maximum value; min - minimum value; $\mathrm{Q}_{25}$ - lower quartile; Me - median; $\mathrm{Q}_{75}$ - upper quartile; $Z$ - value of the Mann-Whitney $U$-test statistic; $p$ - probability value.

$* \alpha=0.05$.

Table 3. Body build of the study subjects

\begin{tabular}{|l|c|c|c|c|c|c|}
\hline \multirow{2}{*}{\multicolumn{1}{|c|}{ Body type }} & \multicolumn{2}{c|}{ Women } & \multicolumn{2}{c|}{ Men } & \multicolumn{2}{c|}{ Total } \\
\cline { 2 - 7 } & $n$ & $\%$ & $n$ & $\%$ & $n$ & $\%$ \\
\hline Underweight & 3 & 5.0 & 0 & 0.0 & 3 & 3.0 \\
\hline Correct & 48 & 83.0 & 21 & 52.0 & 69 & 70.0 \\
\hline Overweight & 7 & 12.0 & 17 & 43.0 & 24 & 25.0 \\
\hline Obesity & 0 & 0.0 & 2 & 5.0 & 2 & 2.0 \\
\hline Total & 58 & 100.0 & 40 & 100.0 & 98 & 100.0 \\
\hline Chi-squared test & \multicolumn{3}{|c|}{$\chi^{2}(3)=16.99 ; p=0.001 *$} \\
\hline
\end{tabular}

Abbreviations: $n$ - number of subjects; \% - percent of subjects; $\chi^{2}-$ value of the Chi-squared test statistic; $p$ - probability value.

$* \alpha=0.05$.

Data in Table 2 indicate that men were characterized by higher values of body weight $(p<0.001)$, body height $(p<0.001)$ and BMI $(p<0.001)$.

The Chi-squared test indicated statistically significant relationships between the prevalence of given body types and the subjects' gender $(p=0.001)$. Women more often were of normal weight or underweight, while men were overweight or obese (Table 3).

\section{Examination protocol}

Anteroposterior curvatures of the spine was measured using Baseline digital inclinometer (The Saunders Group Inc., USA) at the following topographic points: the sacral midpoint ( $\alpha$ angle), $\mathrm{Th}_{12}-\mathrm{L}_{1}$ intervertebral space ( $\beta$ angle) and $\mathrm{C}_{7}-\mathrm{Th}_{1}$ intervertebral space ( $\gamma$ angle), with the accuracy of $2^{\circ}$. The manner of taking of measurements is shown in Fig. 1.

The tests were carried out in the morning, in a warm, well-lit room. The examined person stood in a free position so that the feet were hip-width apart and the toes were in one line. In order to avoid measuring errors, before the start of the measurements, the meas- uring points were marked on the body of each examined individual with a dermograph: $\mathrm{C}_{7}$ spinous process, thoracolumbar transition, a line connecting the lower aspects of the upper posterior iliac spines. Before each measurement, the inclinometer was set to the base position (zeroed in relation to the vertical line) and the results were read perpendicular to the device. Measurement data were referenced to general Saunders standards [26]:

- Lumbosacral angle ( $\alpha$ angle) - the norm: $15-30^{\circ}$;

- Thoracic kyphosis curvature ( $\beta$ angle $+\gamma$ angle) - the norm: $30-40^{\circ}$;

- Lumbar lordosis curvature ( $\alpha$ angle $+\beta$ angle) - the norm: $30-40^{\circ}$.

From the measurement data, the compensation ratio $(\mu)$ was calculated according to the ZeylandMalawka formula [29]:

$$
\mu=\mathrm{KKP}-\mathrm{KLL},
$$

where:

KKP - thoracic kyphosis curvature,

KLL - lumbar lordosis curvature. 


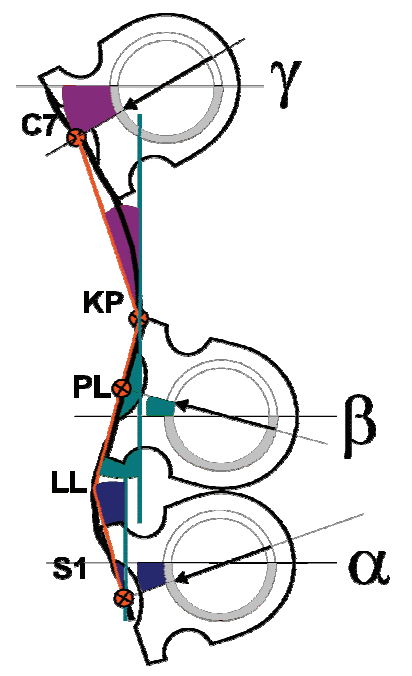

Fig. 1. Diagram showing the manner of applying the inclinometer at designated topographic points [27]. Abbreviations: $\mathrm{KP}$ - thoracic kyphosis,

$\mathrm{PL}$ - thoracolumbar transition; LL - lumbar lordosis $\alpha$-angle of inclination of the lumbosacral section of the spine, $\beta$ - angle of inclination of the thoracolumbar section of the spine, $\gamma$ - angle of inclination of the upper thoracic section of the spine

Body posture types and subtypes were determined according to Wolański's typology [28].

Balanced type of posture (R) was assumed as such where the angular difference between the thoracic and lumbar curvature was within the range of 0 to $5^{\circ}$. Therefore, the following subtypes were distinguished:

- R I - when the difference between Th and L was from 0 to $2^{\circ}$,

- R II - when the difference between Th and L was from 3 to $4^{\circ}$,

- R III - when the difference between Th and L was $5^{\circ}$.

The kyphotic type of posture $(\mathrm{K})$ was assumed as such where the angle of thoracic curvature was greater than the angle of lumbar curvature by more than $5^{\circ}$. Therefore, the following subtypes were distinguished:

- K I - the norm $\left(6-10^{\circ}\right)$,

- K II - slight deviation from the norm $\left(11-15^{\circ}\right)$,

- K III - significant deviation from the norm $\left(16-20^{\circ}\right.$ and above).

The lordotic type of posture (L) was assumed as such where the angle of lumbar curvature was greater than the angle of thoracic curvature by more than $5^{\circ}$. Therefore, the following subtypes were distinguished:

- L I: the norm $\left(6-10^{\circ}\right)$,

- L II: slight deviation from the norm $\left(11-15^{\circ}\right)$,

- L III: significant deviation from the norm (16-20 and above).

In order to ensure overall integrity of the research process, all tests were carried out in the morning, using the same measuring instrument operated by the
Authors. The measurements were carried out in a gym. Study participants wore their underwear, and were barefooted. All study protocol procedures were pursued in full compliance with the Helsinki Declaration. All participants received detailed information regarding the study aims and attendant methods to be applied. The study protocol was approved by the Bioethics Review Committee, University of Rzeszów (Approval Ref. No. 3/12/2015).

\section{Statistical analysis}

Based on the data collected, the following descriptive statistical calculations were made. Consistency of pertinent variables with reference values in normal distribution was verified by means of the Shapiro-Wilk test. To assess intergroup differences in the average level of numerical features, Student's $t$-test for independent samples or, alternatively, Mann-Whitney $U$-test were applied. The analysis of qualitative data was carried out using the Pearson Chi-squared test. The results were considered statistically significant on the predetermined significance level $\alpha=0.05$. The Stat Soft STATISTICA application (version 13.1) was used to process all test results.

\section{Results}

Data collected in Table 4 indicate the occurrence of statistically significant inter-gender differences in the values of angles determining the inclination of lumbosacral section of the spine ( $\alpha$ angle) $p<0.001$, the lumbar lordosis curvature $(p<0.001)$, as well as the compensation ratio $(p=0.002)$.

The prevalence of abnormal inclination of lumbosacral section of the spine, based on the $\alpha$ angle, was gender-dependent $(p<0.001)$. In men, abnormal values of the $\alpha$ angle were found more often. Gender also determined the prevalence of lumbar lordosis abnormalities $(p=0.001)$. Men more often had abnormal lumbar lordosis (Table 5).

A more detailed analysis focused on the deviations in the spinal curvatures - in terms of their shallowing or deepening confirmed the lack of correlation between the prevalence of individual categories of thoracic kyphosis and the subjects' gender $(p=0.661)$, and statistically significant dependences between the lumbar lordosis curvature and the subjects' gender ( $p$ $<0.001)$. In women, normal or increased lumbar lordosis curvature was more often noted, while in men, the lumbar lordosis was more shallow (Table 6). 
Table 4. Comparison of values of angles determining the shape of the anteroposterior spinal curvatures and the compensation ratio in the study subjets

\begin{tabular}{|c|c|c|c|c|c|c|c|}
\hline Gender & $\bar{x} \pm \mathrm{SD}$ & Max-min & $\mathrm{Q}_{25}$ & $\mathrm{Me}$ & $\mathrm{Q}_{75}$ & $t / Z$ & $p$ \\
\hline \multicolumn{8}{|c|}{ Inclination of the lumbosacral section of the spine ( $\alpha$ angle) $\left[{ }^{\circ}\right]$} \\
\hline Women & $18.70 \pm 4.01$ & $26.70-6.00$ & 17.30 & 19.50 & 20.70 & \multirow{2}{*}{$Z=6.33$} & \multirow{2}{*}{$<0.001^{*}$} \\
\hline Men & $12.66 \pm 3.68$ & $20.50-5.30$ & 10.55 & 12.80 & 15.30 & & \\
\hline \multicolumn{8}{|c|}{ Inclination of the thoracolumbar section of the spine $(\beta$ angle $)\left[^{\circ}\right]$} \\
\hline Women & $14.01 \pm 3.89$ & $23.00-4.80$ & 11.30 & 14.10 & 16.80 & \multirow{2}{*}{$t=0.59$} & \multirow{2}{*}{0.555} \\
\hline Men & $13.46 \pm 5.31$ & $24.00-1.00$ & 9.35 & 14.20 & 17.15 & & \\
\hline \multicolumn{8}{|c|}{ Inclination of the upper thoracic section of the spine $(\gamma$ angle $)\left[{ }^{\circ}\right]$} \\
\hline Women & $18.09 \pm 6.13$ & $35.40-9.50$ & 13.50 & 16.65 & 22.20 & \multirow{2}{*}{$Z=1.13$} & \multirow{2}{*}{0.256} \\
\hline Men & $17.30 \pm 7.55$ & $33.40-7.20$ & 10.75 & 15.35 & 23.20 & & \\
\hline \multicolumn{8}{|c|}{ Thoracic kyphosis curvature $\left[^{\circ}\right]$} \\
\hline Women & $32.10 \pm 6.85$ & $48.00-19.00$ & 27.50 & 31.50 & 36.40 & \multirow{2}{*}{$t=0.83$} & \multirow{2}{*}{0.410} \\
\hline Men & $30.77 \pm 9.14$ & $48.70-11.50$ & 21.70 & 32.00 & 37.85 & & \\
\hline \multicolumn{8}{|c|}{ Lumbar lordosis curvature $\left[{ }^{\circ}\right]$} \\
\hline Women & $32.72 \pm 6.09$ & $45.50-12.00$ & 28.70 & 32.55 & 36.10 & \multirow{2}{*}{$t=5.00$} & \multirow{2}{*}{$<0.001^{*}$} \\
\hline Men & $26.12 \pm 6.84$ & $41.50-8.10$ & 21.15 & 26.55 & 30.05 & & \\
\hline \multicolumn{8}{|c|}{ Compensation ratio $(\mu)\left[^{\circ}\right]$} \\
\hline Women & $-0.61 \pm 7.58$ & $17.40-(-11.60)$ & -6.50 & -1.50 & 3.80 & \multirow{2}{*}{$Z=-3.11$} & \multirow{2}{*}{$0.002 *$} \\
\hline Men & $4.64 \pm 8.00$ & $22.10-(-8.90)$ & -1.80 & 3.45 & 10.70 & & \\
\hline
\end{tabular}

Abbreviations: $\bar{x}$ - arithmetical mean value; $\mathrm{SD}$ - standard deviation; $\max$ - maximum value; min - minimum value; $\mathrm{Q}_{25}$ - lower quartile; Me - median; $\mathrm{Q}_{75}$ - upper quartile; $t$ - value of the Student's $t$-test statistic; $Z$ - value of the Mann-Whitney $U$-test statistic; $p$ - probability value.

$* \alpha=0.05$.

Table 5. Frequency of abnormalities in lumbosacral inclination, curvature of thoracic kyphosis and lumbar lordosis depending on gender

\begin{tabular}{|l|c|c|c|c|c|c|}
\hline \multirow{2}{*}{ Value } & \multicolumn{2}{c|}{ Women } & \multicolumn{2}{c|}{ Men } & \multicolumn{2}{c|}{ Total } \\
\cline { 2 - 7 } & $n$ & $\%$ & $n$ & $\%$ & $n$ & $\%$ \\
\hline Inclination of the lumbosacral section of the spine $(\alpha$ angle) \\
\hline Correct & 51 & 88.0 & 11 & 27.0 & 62 & 63.0 \\
\hline Incorrect & 7 & 12.0 & 29 & 73.0 & 36 & 37.0 \\
\hline Chi-squared test & \multicolumn{7}{|c|}{$\chi^{2}(1)=37.19 ; p<0.001 *$} \\
\hline \multicolumn{7}{|c|}{ Thoracic kyphosis curvature } \\
\hline Correct & 27 & 47.0 & 15 & 38.0 & 42 & 43.0 \\
\hline Incorrect & 31 & 53.0 & 25 & 62.0 & 56 & 57.0 \\
\hline Chi-squared test & \multicolumn{7}{|c|}{$\chi^{2}(1)=0.79 ; p=0.373$} \\
\hline \multicolumn{7}{|c|}{ Lumbar lordosis curvature } \\
\hline Correct & 33 & 57.0 & 9 & 23.0 & 42 & 43.0 \\
\hline Incorrect & 25 & 43.0 & 31 & 77.0 & 56 & 57.0 \\
\hline Chi-squared test & \multicolumn{7}{|c|}{$\chi^{2}(1)=11.43 ; p=0.001 *$} \\
\hline
\end{tabular}

Abbreviations: $n$ - number of subjects; \% - percent of subjects; $\chi^{2}$ - value of the Chi-squared test statistic; $p$ - probability value.

$* \alpha=0.05$.

Data collected in Table 7 indicate that the prevalence of body posture types was gender-dependent ( $p$ $=0.005)$. In women, lordotic type was more often observed, while balanced body posture type in men. In turn, the prevalence of individual subtypes of body posture was not gender-dependent. 
Table. 6. Prevalence of individual categories of anteroposterior curvatures of the spine depending on gender

\begin{tabular}{|l|c|c|c|c|c|c|}
\hline \multirow{2}{*}{ Value } & \multicolumn{2}{c|}{ Women } & \multicolumn{2}{c|}{ Men } & \multicolumn{2}{c|}{ Total } \\
\cline { 2 - 7 } & $n$ & $\%$ & $n$ & $\%$ & $n$ & $\%$ \\
\hline \multicolumn{7}{|c|}{ Thoracic kyphosis curvature } \\
\hline Decrease & 23 & 40.0 & 18 & 45.0 & 41 & 42.0 \\
\hline Norm & 27 & 47.0 & 15 & 38.0 & 42 & 43.0 \\
\hline Increase & 8 & 13.0 & 7 & 17.0 & 15 & 15.0 \\
\hline Chi-squared test & \multicolumn{7}{|c|}{$\chi^{2}(2)=0.83 ; p=0.661$} \\
\hline \multicolumn{7}{|c|}{ Lumbar lordosis curvature } \\
\hline Decrease & 18 & 31.0 & 30 & 75.0 & 48 & 49.0 \\
\hline Norm & 33 & 57.0 & 9 & 23.0 & 42 & 43.0 \\
\hline Increase & 7 & 12.0 & 1 & 2.0 & 8 & 8.0 \\
\hline Chi-squared test & 7 & \multicolumn{7}{c|}{$\chi^{2}(2)=18.53 ; p<0.001 *$} \\
\hline
\end{tabular}

Abbreviations: $n$ - number of subjects; $\%$ - percent of subjects; $\chi^{2}$ - value of the Chi-squared test statistic; $p$ - probability value.

$* \alpha=0.05$.

Table 7. Prevalence of body posture types and subtypes depending on gender

\begin{tabular}{|c|c|c|c|c|c|c|c|}
\hline \multirow{2}{*}{\multicolumn{2}{|c|}{ Type of body posture }} & \multicolumn{2}{|c|}{ Women } & \multicolumn{2}{|c|}{ Men } & \multicolumn{2}{|c|}{ Total } \\
\hline & & $n$ & $\%$ & $n$ & $\%$ & $n$ & $\%$ \\
\hline \multicolumn{2}{|l|}{ Balanced } & 28 & 48.0 & 21 & 53.0 & 49 & 50.0 \\
\hline \multicolumn{2}{|l|}{ Kyphotic } & 11 & 19.0 & 16 & 40.0 & 27 & 28.0 \\
\hline \multicolumn{2}{|l|}{ Lordotic } & 19 & 33.0 & 3 & 7.0 & 22 & 22.0 \\
\hline \multicolumn{2}{|c|}{ Chi-squared test } & \multicolumn{6}{|c|}{$\chi^{2}(2)=10.61 ; p=0.005^{*}$} \\
\hline \multirow{3}{*}{ Balanced } & R I & 17 & 61.0 & 9 & 43.0 & 26 & 53.0 \\
\hline & R II & 9 & 32.0 & 10 & 48.0 & 19 & 39.0 \\
\hline & R III & 12 & 7.0 & 2 & 9.0 & 4 & 8.0 \\
\hline \multicolumn{2}{|c|}{ Chi-squared test } & \multicolumn{6}{|c|}{$\chi^{2}(2)=1.54 ; p=0.462$} \\
\hline \multirow{3}{*}{ Kyphotic } & K I & 5 & 46.0 & 6 & 38.0 & 11 & 40.0 \\
\hline & K II & 3 & 27.0 & 5 & 31.0 & 8 & 30.0 \\
\hline & K III & 3 & 27.0 & 5 & 31.0 & 8 & 30.0 \\
\hline \multicolumn{2}{|c|}{ Chi-squared test } & \multicolumn{6}{|c|}{$\chi^{2}(2)=0.17 ; p=0.918$} \\
\hline \multirow{3}{*}{ Lordotic } & L I & 17 & 90.0 & 3 & 100.0 & 20 & 91.0 \\
\hline & L II & 2 & 10.0 & 0 & 0.0 & 2 & 9.0 . \\
\hline & L III & 0 & 0.0 & 0 & 0.0 & 0 & 00 \\
\hline \multicolumn{2}{|c|}{ Chi-squared test } & \multicolumn{6}{|c|}{$\chi^{2}(1)=0.35 ; p=0.555$} \\
\hline
\end{tabular}

Abbreviations: $n$ - number of subjects; $\%$ - percent of subjects; $\chi^{2}-$ value of the Chi-squared test statistic; $p$ - probability value.

$* \alpha=0.05$.

\section{Discussion}

Our study indicated that people practicing ballroom dance experience inter-gender differences in the angular values of the angle determining the inclination of lumbosacral section of the spine ( $\alpha$ angle), the lumbar lordosis curvature and compensation ratio. Women are characterized with greater the lumbosacral inclination and deeper lumbar lordosis. These results are consistent with the findings of Roussouly and
Pinheiro-Franco [25], who pointed out to the relationship between lumbar lordosis and sacral inclination. According to the authors, the increase in the sacral inclination is accompanied by a deepening of the lumbar lordosis curvature (the so-called "dynamic retraction"), while the horizontal orientation of the sacrum coincides with the flattening of the lumbar lordosis (the so-called "flatback"). Ambegaonkar et al. [1], in the study using a 2-dimensional sagittal plane photographs and the Watson Mac Donncha Posture Analysis instrument, found that women with the mean age of $20.20 \pm 1.60$ years, 
practicing dance, are characterized by increased lumbar lordosis. The authors pointed to the relationship between deepened lumbar lordosis and hyperextension movements of the lumbar spine during exercises and dance performances. This observation can be considered legitimate, because performing large-range movements during dancing can contribute to the deepening of lumbar lordosis. This problem does not occur so often among men, because, compared to women, their dance position, figures and steps do not require such large hyperextension of the lumbar spine. In addition, it is worth emphasizing that the shape the spinal curvatures and motor control of the lumbarpelvic complex in women practicing dance can be influenced by high-heeled shoes, which amateur and professional dancers wear during training and performances. Also, Fong Yan et al. [7] claim that the characteristic dance position adopted by the dancers and the movement in dance shoes are associated with significant changes in the spinal curvatures. In turn, Gottschlich et al. [10] and Ball et al. [2] stressed that wrong dance technique is the cause of muscular imbalances of the spine, which may lead to hyperlordosis.

Analysis of the values of the compensation ratio indicates that the sagittal deviation of the spine is a problem affecting both sexes, except that in women the lumbar lordosis curvature is greater compared to the thoracic kyphosis curvature, whereas, in the case of men, these proportions are inverse. Men have a greater difference in the depth of thoracic kyphosis curvature and lumbar lordosis curvature. While interpreting the data obtained, it is worth considering the report by Elsayed et al. [6], who pointed out to the relationship between the balance of the spine in the sagittal plane and the strength of the muscles of the abdomen and lumbar spine. According to Małecki et al. [16] and Rickman et al. [24], the shape of the anteroposterior curvatures of the spine can be associated with long-term, forced position of the spine during dance or activity of the abdominal muscles, which are the main stabilizers of the pelvis and lumbar spine.

In our material, based on the gender of the people being examined, the frequency of abnormal inclination of lumbosacral section of the spine and the shape of the lumbar lordosis curvature could be determined. Men were characterized by abnormal values of the $\alpha$ angle indicating smaller lumbosacral inclination, as well as shallowing of lumbar lordosis. In women, the physiological shape or increased lumbar lordosis curvature were more common. There are few studies on dance, and they were mainly focused on Latin American style, ballet or flamenco dance professionals. Most authors suggest that body positions required for dance cause dangerous hyperflexia mainly in the lumbar spine. The study by Muyor et al. [19] indicated with the Spinal Mouse device that the spine of Latin American style dancers compared to non-dancers is characterized by greater flexibility and deepening of the lower part of thoracic kyphosis, lumbar lordosis, as well as greater anterior pelvic tilt in standing position. Pohjola et al. [22] claim that even among professional dancers the control of the lumbopelvic complex is disturbed. These abnormalities can contribute to changes throughout the kinetic chain and pose a risk factor for injury during dance. This suggests that learning how to control anterior tilt and spine mobility in dancers' training may be an important element in preventing locomotor abnormalities. In turn, Koutedakis et al. [15] claim that the cause of excessive lumbar lordosis is the imbalance between the quadriceps and the hamstings, which determine the correct lumbar-pelvic rhythm and the distribution of forces affecting the spine.

Gómez-Lozano et al. [11], based on inclinometric measurements, found that the thoracic kyphosis of flamenco dancers with an average age of $22.12 \pm 4.21$ years shows a tendency to elongation and flattening, mainly due to the specific dance technique, where, especially during the castanets play, there is a strong backward tilt of the torso and chest prominence. The authors emphasized that the decrease of thoracic curvature predisposes to a decrease in the cushioning function of the spine, and thus to intervertebral disc damage. Therefore, at the early stages of training, ballet training should be undertaken parallel to flamenco, and the training process should include exercises to improve the flexibility of this part of the spine. At the same time, they emphasize that this style of dance can be a complementary measure in therapeutic management in the case of thoracic hyperkyphosis. The values determining the shape of lumbar lordosis of the studied dancers were within normal limits. According to d'Hemecourt and Luke [5], classical ballet is based on maintaining a stable center (core). This allows the lower limbs to make free movements. However, some ballet positions can cause more risky movement of the lumbar-pelvic complex. Among the causes of deepened lordosis in ballerinas, the author enumerated the predominance of the extension movements of this part of the spine, most often caused by weakening of the abdominal and gluteal muscles. Calvo et al. [3] found greater abdominal muscle tone in flamenco dancers compared to people practicing classical dance. This would explain the discrepancies in the formation of lumbar lordosis of flamenco 
dancers in relation to women qualified for our study, although the final resolution of this issue requires separate study. Therefore, in future research projects it is worth considering whether women's lordotic posture is caused by repetitive stretching movement or lack of initial training in the proper control of the muscles responsible for the static and dynamic position of the pelvis. This assessment is a difficult and complex issue. Given the individual variability of body posture, it is difficult to determine its regularity, taking into account all the endo- and exogenous conditions of a given person and environmental postureforming interactions. Hence, the limitation of the study is the fact that the formation of anteroposterior curvatures of the spine can be influenced by factors not directly related to practicing dance.

To sum up, it should be considered that this work is an innovative view on the issue regarding the shape of the spine in dancers, mainly due to inter-gender comparisons. The results of our study indicate a tendency to inter-gender differences in the formation of anteroposterior curvatures of the spine. Therefore, it can be concluded that the consequences of dance training in relation to body posture may be different for women and men. The results of our study may help clinicians to identify dancers with body posture disorders, and thus with a higher risk of injury. This way preventive intervention strategies may be developed. An important practical implication is the suggestion of considering gender while creating training programs, research planning and interpretation of obtained data. This is an important premise for planning appropriate preventive strategies, involving work on improving body posture and re-education of proprioception in dancers.

\section{Conclusions}

Compared to men, women practicing ballroom dancing are characterized by a greater values of angles determining the inclination of lumbosacral section of the spine and lumbar lordosis. Men have a higher value of the compensation ratio. In women, the lumbar lordosis curvature is greater compared to the thoracic kyphosis curvature, while in men the proportions are inverse.

The gender of the subjects determines the frequency of deviations in the lumbosacral inclination and the shape of the lumbar lordosis curvature. Men are characterized by abnormal values of the $\alpha$ angle and abnormal shape of lumbar lordosis.
The prevalence of the category of anteroposterior curvature of the spine depends on gender. In women, the correct shape or increased lumbar lordosis curvature are more common, while shallowed lumbar lordosis in men.

The frequency of individual types and subtypes of body posture depends on the sex of the subjects. Women are more likely to have lordotic body posture while men are characterized by balanced body posture. The prevalence of body posture subtypes is not dependent on gender.

\section{References}

[1] Ambegaonkar J.P., Caswell A.M., Kenworthy K.L., CORTES N., CASWELl S.V., Lumbar lordosis in female collegiate dancers and gymnasts, Med. Probl. Perform. Art, 2014, 29 (4), 189-192, DOI: 10.21091/mppa.2014.4039.

[2] BAll J.R., HARRis C.B., LEE J., VIVES M.J., Lumbar spine injuries in sports: review of the literature and current treatment recommendations, Sports Med. - Open, 2019, 26 (5), DOI: 10.1186/s40798-019-0199-7.

[3] Calvo J.B., Alonso A., Pasadolos A., Gómez-Pellico L., Flamenco dancing. Biomechanical analysis and injuries prevention, [in:] A. Macara (Ed.), Continents in Movement. Proceedings of the International Conference. New trends in dance teaching, Ediçoes, Oeiras, 1998, 279-285.

[4] Contes J.E., Mcgregor A.H., Beith I.D., Hughes S.P., The influence of initial resting posture on range of motion of the lumbar spine, Man. Ther., 2001, 6 (3), 139-144, DOI: 10.1054/math.2001.0397.

[5] D'hemecourt P.A., Luke A., Sport-specific biomechanics of spinal injuries in aesthetic athletes (dancers, gymnasts, and figure skaters), Clin. Sports Med., 2012, 31 (3), 397-408, DOI: 10.1016/j.csm.2012.03.010.

[6] Elsayed W., Farrag A., Muaidi Q., Almulhim N., Relationship between sagittal spinal curves geometry and isokinetic trunk muscle strength in adults, Eur. Spine J., 2018, 27 (8), 2014-2022, DOI: 10.1007/s00586-017-5454-3.

[7] Fong Yan A., Hiller C., Smith R., Vanwanseele B., Effect of footwear on dancers: a systematic review, J. Dance Med. Sci., 2011, 15 (2), 86-92.

[8] Fredryk A., SMol E., Dance, rhythm, music in science and practice, AWF, Katowice 2014.

[9] GoRwA J., The problem of back pain in professional dancers, Aktualne Problemy Biomechaniki, 2016, 10, 17-24.

[10] GotTschlich L.M., Young C.C., Spine Injuries in Dancers. Curr. Sports Med. Rep., 2011, 10 (1), 40-44. DOI: 10.1249/ JSR.0b013e318205e08b.

[11] Gómez-Lozano S., Vargas-Macías A., Santonja Medina F., Canteras Jordana M., Descriptive study of sagittal spinal morphotype in female flamenco dancers, Rev. Cent. Investig. Flamenco Telethusa, 2013, 6 (7), 19-28.

[12] GzIK M., Biomechanika kręgostupa, Wydawnictwo Politechniki Śląskiej, Gliwice 2007.

[13] Iunes D.H., Elias I.F., Carvalho L.C., Dionísio V.C., Postural adjustments in young ballet dancers compared to age matched controls, Phys. Ther. Sport, 2016, 17, 51-57, DOI: 10.1016/j.ptsp.2015.04.004. 
[14] Kiefer A.W., Riley M.A., Shockley K., Sitton C.A., HewetT T.E., Cummins-SeBreE S., HAAS J.G., Multi-segmental postural coordination in professional ballet dancers, Gait Posture, 2011, 34 (1), 76-80, DOI: 10.1016/j.gaitpost.2011.03.016.

[15] Koutedakis Y., Owolabi E., Apostolos M., Dance biomechanics: a tool for controlling health, fitness, and training, J. Dance Med. Sci., 2008, 12 (3), 83-90.

[16] MaŁecki J., Kokosz M., SAulicz E., Świat-BorowczyK I., The effectiveness of stability training of the lumbo-pelvichip complex in ballroom dancers with low back pain, Physiotherapy and Health Activity, 2015, 23, 16-21, DOI: 10.1515/pha-2015-0010.

[17] Micheli L.J., Back injuries in dancers, Clin. J. Sport Med., 1983, 2 (3), 473-484.

[18] Moller A., Masharawi Y., The effect of first ballet classes in the community on various postural parameters in young girls, Phys. Ther. Sport, 2011, 12 (4), 188-193, DOI: 10.1016/ j.ptsp.2011.04.001.

[19] Muyor J.M., Zemková E., Chren M., Effects of latin style professional dance on the spinal posture and pelvic tilt, J. Back Musculoskelet. Rehabil., 2017, 30 (4), 791-800, DOI: 10.3233/BMR-150448.

[20] Paris-Alemany A., Torres-Palomino A., Marino L., Calvo-Lobo C., Gadea-Mateos L., La Touche R., Comparison of lumbopelvic and dynamic stability between dancers and non-dancers, Phys. Ther. Sport, 2018, 33, 33-39, DOI: 10.1016/j.ptsp.2018.06.010.

[21] Perrin P., Deviterne D., Hugel F., Perrot C., Judo, better than dance, develops sensorimotor adaptabilities involved in balance control, Gait Posture, 2002, 15 (2), 187-194, DOI: 10.1016/s0966-6362(01)00149-7.

[22] Pohjola H., Vartiainen P., Karjalainen P.A., Stenroth L., VENOJÄRVI M., Lumbopelvic movement control in contemporary dancers: A multiple case study, Trans Sport Med., 2019, 2 (4), 214-220, https://doi.org/10.1002/tsm2.81.

[23] Ribeiro J.N., Soares De Moura U.I., Mendes L.R., Antonelli B.A., Schwingel P.A., Di CASSia De Oliveira ANGelo R. Postural profile of classical ballerinas from the Vale do São Francisco region of Brazil, Columna, 2016, 15, 199-204, DOI:10.1590/S1808-185120161503155900.

[24] Rickman A.M., Ambegaonkar J.P., CoRTes N., Core stability: implications for dance injuries, Med. Probl. Perform. Art, 2012, 27 (3), 159-164.

[25] Roussouly P., PinheIro-Franco J.L., Biomechanical analysis of the spino-pelvic organization and adaptation in pathology, Eur. Spine J., 2011, 20(5), 609-618, DOI: 10.1007/ s00586-011-1928-x.

[26] The Saunders Group Incorporated. Saunders digital inclinometer. Instructional materials. Norex Drive, Chaska, 2018.

[27] Walicka-Cupryś K., PuszczaŁowsKa-Lizis E., Maziarz K., The forming of anterior-posterior spinal acurvatures in young people from junior high schools and grammar schools, Med. Rehabil., 2008, 12 (4), 28-36.

[28] WolAŃSKI N., Control methods and development norms for children and adolescents, Warszawa 1975.

[29] ZEYLAND MALAWKA E., Classification and assessment of body posture in modified Wolański method and New York Classification Test, Fizjoter., 1999, 7 (4), 52-55. 